\title{
O Efeito Disposição na Indústria Brasileira de Fundos de Investimento em Ações
}

\author{
Elton Tizziani* \\ Marcelo Cabus Klotzle** \\ Walter Lee Ness Jr.*** \\ Luiz Felipe Motta****
}

\section{Resumo}

Este artigo tem como objetivo testar o efeito disposição, que é a tendência dos investidores em vender os investimentos ganhadores mais rapidamente que os investimentos perdedores, através da análise das carteiras de todos os Fundos Brasileiros de Investimentos em Ações, no período compreendido entre novembro de 2003 e março de 2008. Embora a análise do número de transações revele que os fundos de investimento estão sujeitos ao efeito disposição, diferentemente do mercado acionário americano, quando são analisados os volumes transacionados, não é possível identificar o efeito disposição, especialmente em relação aos fundos de varejo, os que apresentaram a maior tendência de realização de perdas em detrimento dos ganhos.

Palavras-chave: efeito disposição; fundos de investimento em ações; finanças comportamentais.

Códigos JEL: G11; G12; G20.

\section{Abstract}

The goal of this paper is to test the disposition effect, the tendency of investors to sell winning investments too soon and hold losing investments too long, by analyzing all Brazilian equity fund portfolios from November 2003 to March 2008. The analysis based on the number of trades shows that equity funds are subject to the disposition effect. On the other hand, contrary to evidence from the American stock market, when the analysis is based on trading volume, the disposition effect is not found. Finally, the disposition effect is strongest in funds open to non-qualified investors.

Keywords: disposition effect; equity funds; behavioral finance.

Submetido em outubro de 2009. Aceito em maio de 2010. O artigo foi avaliado segundo o processo de duplo anonimato além de ser avaliado pelo editor. Editor responsável: Ricardo P. C. Leal.

*Pontifícia Universidade Católica do Rio de Janeiro, Rio de Janeiro, Brasil.

E-mail: elton@inteligenciaonline.com

**Pontifícia Universidade Católica do Rio de Janeiro, Rio de Janeiro, Brasil.

E-mail: klotzle@iag.puc-rio.br

****Pontifícia Universidade Católica do Rio de Janeiro, Rio de Janeiro, Brasil.

E-mail: ness@iag.puc-rio.br

****Pontifícia Universidade Católica do Rio de Janeiro, Rio de Janeiro, Brasil.

E-mail: lfelipe@iag.puc-rio.br 


\section{Introdução}

O mercado de capitais brasileiro tem apresentado grande evolução nos últimos 10 anos, tornando-se cada vez mais importante para a consolidação do desenvolvimento econômico brasileiro. Esta evolução é suportada, de um lado, pelo aumento da credibilidade do país advinda da continuidade do Plano Real e controle da inflação e dívida externa. Por outro lado, o mercado brasileiro vem evoluindo em termos de regulação, tornando-se mais confiável para os investidores nacionais e estrangeiros (Velloso, 2008, Filho, 2008).

Embora o mercado de capitais brasileiro já disponha de infra-estrutura ampla, com capacidade para suportar sofisticadas operações financeiras, ainda é subutilizado no financiamento do setor privado e tímido em relação às operações de longo prazo, quando comparado com mercados mais desenvolvidos. Isso, por um lado, pode ser entendido como uma fraqueza nacional, mas, por outro lado, evidencia o potencial de crescimento do mercado brasileiro, especialmente após ter conquistado o grau de investimento (De la Torre et alii, 2008).

O mercado de ações levou muito tempo para ser percebido pelo investidor brasileiro, o qual estava acostumado com taxas de juros estratosféricas, muitas vezes alcançando e permanecendo no posto de mais alta do mundo. Com o equilíbrio econômico e controle da inflação, há uma tendência de redução da taxa básica de juros no longo prazo, o que pode trazer ainda mais movimento financeiro para a bolsa de valores, auxiliando o desenvolvimento do mercado acionário brasileiro (Wald, 2008).

Neste cenário, os fundos de investimento constituem-se em um dos principais mecanismos de entrada do mercado de capitais, já que foram responsáveis por $30 \%$ da movimentação da Bolsa de Valores de São Paulo no ano de 2007, perdendo apenas para os investidores estrangeiros, que movimentaram mais de $37 \%$ do volume total. Embora os fundos de investimento estejam divididos em diversas classes, quando se trata especificamente do mercado acionário, os fundos de ações ganham extrema relevância, visto que eles detêm $83 \%$ das ações que compõem as carteiras de todos os fundos de investimento (ANBID, 2008).

A forma pela qual os investimentos são realizados pode estar relacionada exclusivamente a uma técnica, mas também pode envolver traços do comportamento do investidor. Assim, nos últimos anos, tem sido dada grande importância a uma linha de pesquisa chamada de Finanças Comportamentais, que incorpora teorias não-exatas à precificação dos ativos, provenientes de outras áreas de conhecimento tais como Psicologia e Sociologia. A hipótese principal por trás da linha de pesquisa das Finanças Comportamentais é que o investidor nem sempre segue os preceitos das Finanças Modernas na hora de tomar decisões de investimentos, preceitos estes, baseados amplamente na Teoria da Utilidade Esperada. (Ackert e Deaves, 2010). Ao contrário, na maioria das vezes, na hora de tomar decisões importantes envolvendo risco, os investidores cometem desvios do que se esperaria de uma decisão racional, desvios esses conhecidos como ilusões cognitivas (Kahneman et alii, 1982). Tversky e Kahneman (1974) enfatizam também o conceito 
de probabilidade subjetiva, que mostra como certas heurísticas e vieses fazem com que as pessoas se desviem de uma tomada de decisão racional baseada em regras concretas de probabilidade. Eles citam a representatividade, a disponibilidade e a ancoragem como principais vieses e heurísticas básicos influenciando a avaliação de probabilidades objetivas.

Dentro desses desvios do comportamento racional está inserido o efeito disposição, que é definido como a tendência dos investidores em venderem mais rapidamente seus ativos com ganhos em detrimento daqueles que apresentam perdas de capital. O efeito disposição é resultante da Teoria do Prospecto, desenvolvida por Kahneman e Tversky (1979), que prediz que os tomadores de decisão tendem a ser avessos ao risco quando estão no campo dos ganhos e propensos ao risco quanto estão no campo das perdas (Barberis e Xiong, 2009).

O objetivo principal deste artigo é testar o efeito disposição no mercado brasileiro de fundos de investimento em ações no período de novembro de 2003 a março de 2008. Para analisar o efeito disposição, foi testada a hipótese de que a proporção de ganhos realizados é superior à proporção de prejuízos realizados, replicando a metodologia desenvolvida por Odean (1998). Os resultados mostram que não é possível comprovar o efeito disposição quando são considerados os volumes transacionados. O efeito disposição só se mostra visível, e mesmo assim com baixa significância estatística, quando é considerado apenas o número de transações realizadas pelos fundos de investimentos para fins de cômputo do percentual de ganhos e perdas realizadas.

Esse artigo contribui para o estudo das Finanças Comportamentais devido ao fato de o efeito disposição ser de grande relevância nos mercados financeiros, já que exerce grande influência no comportamento do investidor e, por conseguinte na formação do preço dos ativos no mercado. Além do mais, ele não é só um fenômeno que acontece nos mercados desenvolvidos, mas também em mercados emergentes. Por fim não afeta somente o mercado secundário de ações, mas também se aplica a Ofertas Públicas Iniciais e também no mercado futuro, como provam estudos recentes (Brown et alii, 2006, Choe e Eom, 2009).

Em relação a outros estudos já feitos no Brasil esse artigo se diferencia por testar o efeito disposição através da negociação de fundos de investimento em ações em um período mais recente que outros estudos. Como dito anteriormente, fundos de investimento em ações representam no Brasil um dos principais mecanismos de entrada no mercado de capitais e é de se esperar que as transações efetuadas por parte dos gestores dos fundos exerçam influência na formação dos preços dos ativos. Além disso, e como será detalhado posteriormente na metodologia, a base para as composições das carteiras teóricas foi o IBrX-50 e não o Ibovespa. O IBrX-50 é um índice quadrimestral composto por 50 ações escolhidas em termos de liquidez, ponderado pela capitalização de mercado das ações disponíveis para negociação que integram o índice. Este último critério constitui-se no diferencial de escolha do IBrX-50 em detrimento do Ibovespa, índice de maior divulgação no 
mercado de capitais brasileiro, já que este último pondera a participação das empresas de acordo com o número de negócios e volume financeiro transacionado (BMFBOVESPA, 2010).

De forma a testar o efeito disposição, o artigo está assim dividido: na próxima seção será apresentada a linha de pesquisa em Finanças Comportamentais, incluindo a teoria do prospecto, da qual advém o efeito disposição, e estudos sobre o próprio efeito disposição, realizados tanto no Brasil como em outros mercados. Depois da análise da base teórica do estudo, será descrita a metodologia, que contempla a coleta de dados bem como a descrição do teste empírico realizado com as carteiras dos fundos de investimento em ações no período de novembro de 2003 a março de 2008. Em seguida serão apresentados os resultados dos testes efetuados e as conclusões sobre tais resultados. A partir daí é apresentada uma breve discussão, além de recomendações para testes futuros.

\section{Referencial Teórico}

Muitos autores defendem que a Teoria Moderna de Finanças surgiu a partir das premissas de racionalidade dos tomadores de decisão e da imprevisibilidade dos mercados, o que se constituiu numa ruptura à Teoria Tradicional de Finanças que defendia a previsibilidade dos mercados e a concentração dos investimentos.

Diversos estudos foram fundamentais para a consolidação da Teoria Moderna de Finanças, dentre os quais merecem destaque os de Markowitz (1952), Miller e Modigliani (1961), Sharpe (1964), Fama (1970) entre outros.

Tal teoria está calcada em diversas hipóteses, quais sejam: concorrência perfeita; homogeneidade das expectativas; racionalidade na tomada de decisões; e ausência de fricções (ativos homogêneos, divisíveis e ausência de custos de transações). Fama (1970) acrescenta ainda que, uma vez que as informações são compartilhadas uniformemente no mercado, informações e notícias passadas não podem ser utilizadas como vantagem competitiva, já que elas estariam refletidas no preço. De acordo com o autor, distorções nos preços seriam rapidamente corrigidas pela presença de arbitradores.

Nos últimos anos, diversos artigos têm fornecido evidências de que existem desvios na Hipótese de Mercados Eficientes, da racionalidade do mercado, a qual não é capaz de explicar por completo a formação de preço e a tomada de decisão do investidor.

As finanças comportamentais estudam o comportamento do investidor, particularmente no que tange à forma como ele toma a decisão. Ela considera que os investidores não agem sempre racionalmente e que muitas vezes são afetados por ilusões cognitivas (tendência dos investidores a cometerem erros sistemáticos de avaliação) que na maioria das vezes são prejudiciais aos investidores (Nofsinger, 2001). Além do efeito disposição, que é objeto deste artigo, podemos citar, por exemplo, o excesso de confiança como outra ilusão cognitiva, que é a tendência dos investidores em sobreestimar a exatidão das informações de que dispõem ou de superestimar seu nível de conhecimento em relação a outros agentes do mer- 
cado. Isto acaba levando-os a transacionar mais frequentemente do que deveriam, incorrendo em altos custos de transação (Barber e Odean, 2001).

Kahneman e Tversky (1979), em sua Teoria do Prospecto, criticam a Teoria da Utilidade Esperada e mostram, que, diante de situações de risco, nem sempre o indivíduo age no sentido de maximizar o retorno esperado. Os autores mostram que, em diversas situações, os indivíduos são avessos ao risco e escolhem as opções mais certas (mesmo que tenham menor valor esperado), o que foi chamado de efeito certeza. No mesmo estudo também pode ser visto o efeito reflexão, pelo qual os indivíduos preferem uma possibilidade de perda ao invés de uma perda certa, mesmo que a primeira tenha um valor esperado mais negativo, mostrando-se propensos ao risco quando se trata de perdas. Os resultados obtidos por Kahneman e Tversky (1979) mostram inconsistências na Teoria da Utilidade Esperada.

O estudo de Kahneman e Tversky (1979) por sua vez se baseou, entre outros, em resultados obtidos anos antes por Maurice Allais, que através de experimentos com jogos confirmou violações ao axioma da substituição da teoria da utilidade esperada. Esses resultados ficaram conhecidos como o "paradoxo de Allais" (Allais, 1953).

O efeito disposição foi introduzido nos estudos sobre finanças comportamentais por (Shefrin e Statman, 1985). O efeito disposição refere-se à tendência dos investidores em realizar ganhos muito cedo e manter perdas por muito tempo, o que contraria um bom planejamento tributário no caso de investidores individuais. (Shefrin e Statman, 1985) observam que as considerações sobre impostos sugerem que as perdas sejam realizadas no curto prazo e os ganhos apenas quando passarem a ser considerados como longo prazo, com o intuito de redução da carga tributária total. Em termos de comportamento racional não há razão, portanto, para a existência do efeito disposição, ou seja, para a venda prematura de ações ganhadoras e a manutenção daquelas perdedoras (Barberis e Thaler, 2003). Um ponto importante que influencia o comportamento do investidor e é relevante no efeito disposição é o preço de referência que serve como base para se avaliar os ganhos e perdas derivados da negociação com ações. Segundo Kahneman e Riepe (1998) o preço de referência com que o investidor avalia os ganhos e as perdas é o preço de compra. Ele cita o exemplo em que dois investidores possuem uma quantidade igual da mesma ação, só que enquanto o investidor A pagou inicialmente $\$ 100$, o investidor B pagou \$200 por ação. Kahneman e Riepe (1998) continuam com o exemplo dizendo que o preço por ação era $\$ 160$ ontem e hoje caiu para $\$ 150$, perguntando então quem estaria mais chateado com a queda do preço da ação. Segundo os autores o investidor B estaria propenso a ficar mais aborrecido que o A, visto que ele encara a queda como um aumento do prejuízo, enquanto o $\mathrm{A}$ encara como uma redução do ganho, visto que os preços de referência de ambos, no caso os de aquisição, são diferentes. Entretanto, no caso dos fundos de investimento, que são objeto deste artigo, não se espera que o efeito final de ano ocorra para as transações dos fundos de investimento no Brasil. Isso se deve ao fato do mecanismo de tributação sobre os ganhos de capital nos EUA ser distinto do pra- 
ticado no Brasil. De acordo com as Instruções Normativas n ${ }^{\circ}$ 25/01 e no 487/04, ambas da Receita Federal do Brasil, o imposto sobre a renda é devido no momento do resgate e incide sobre a diferença positiva entre o valor de resgate e valor de aquisição da cota, sendo a tributação definitiva, retida na fonte pelo administrador do fundo e os prejuízos compensáveis apenas com rendimentos de resgates posteriores em fundos da mesma natureza e administrados pela mesma pessoa jurídica. Com isso, o valor da cota é valorizado pelo valor da ação no dia do resgate, ou seja, é indiferente se a ação foi vendida ou continua em carteira.

Mesmo assim a escolha dos fundos de investimento continua adequada para se testar o efeito disposição, visto que estudos posteriores comprovam que o efeito tributário não se sobrepõe ao efeito disposição. Isso é bem claro no estudo de Odean (1998), que será discutido posteriormente.

A partir das conclusões de Shefrin e Statman (1985), diversas pesquisas, baseadas tanto no mercado acionário norte-americano como em outros mercados, fornecem suporte à hipótese de que os investidores tendem a vender as ações lucrativas em detrimento daquelas com prejuízos.

Em 1988, Ferris, Haugen e Makhija publicaram um trabalho em que testaram também o efeito disposição no mercado americano. Ferris et alii (1988) utilizaram dados sobre preços e volumes para as 30 menores ações (valor de mercado baseado em julho de 1983) negociadas no mercado norte-americano entre dezembro de 1981 e janeiro de 1985. O motivo dos autores terem escolhido as 30 menores empresas se baseava em estudos empíricos da época que demonstravam que elas tinham uma maior volatilidade de preço na bolsa. Baseado nesta amostra, os autores compararam volumes negociados da época do estudo com os volumes de negociação históricos. Os resultados confirmaram o efeito disposição, ou seja, o volume negociado no presente era negativamente (positivamente) correlacionado com o volume dos dias precedentes em que o preço das ações era maior (menor) que o preço atual.

Uma das pesquisas mais importantes que testaram o efeito disposição foi o estudo de Odean (1998), que será discutido mais detalhadamente neste trabalho.

Odean (1998) utilizou em seu estudo uma base composta pelos registros de negociação de 10.000 contas de uma grande corretora de valores norte-americana, no período de 1987 a 1993. Depois que os dados foram filtrados, restaram 6.380 contas (apenas aquelas que negociaram ações com dados disponíveis sobre desdobramentos e dividendos), sendo mantidas sem reposição as contas encerradas ao longo do período sob análise.

Odean (1998) testou o efeito disposição analisando as taxas pelas quais os investidores realizam ganhos e perdas relativamente às suas oportunidades de realizarem ganhos e perdas, respectivamente. Subsidiariamente, o autor também investigou a negociação motivada por impostos em dezembro (tendência da realização de perdas no final do ano para compensação de impostos e consequente redução da carga tributária), seguindo o raciocínio desenvolvido por Shefrin e Stat$\operatorname{man}(1985)$. 
Inicialmente foram encontradas as possibilidades de ganho e perda (obtidas pela comparação do preço atual com o preço médio de aquisição) em cada dia de venda de ativos para depois serem verificadas as vendas efetivas, que geraram ganhos ou perdas realizados. As ações que não são negociadas em dia de venda são consideradas ganhos ou perdas não-realizadas. A partir daí, o autor calculou a proporção de ganhos realizados (número de vendas com ganhos, dividido por transações passíveis de ganho antes da venda) e a proporção de perdas realizadas (número de vendas com perdas, dividido por transações passíveis de perda antes da venda). Depois foi aplicado um teste estatístico (estatística t) que rejeitou a hipótese nula de que a proporção dos ganhos realizados é menor ou igual à proporção das perdas realizadas, confirmando o efeito disposição.

A hipótese que define o efeito disposição continua a ser rejeitada mesmo quando é considerada a quantidade de ações em vez do número de transações, e quando a base de dados é dividida em dois períodos (1987 a 1990 e 1990 a 1993) e em dois grupos de investidores (10\% mais frequentes e demais investidores). Mesmo quando foram consideradas apenas as vendas totais (eliminando-se as vendas parciais que poderiam ter sido estimuladas por um rebalanceamento da carteira), os resultados não são alterados significativamente.

O estudo de Odean (1998) também mostra um estudo pós-evento dos retornos excedentes das ações transacionadas na amostra em três períodos distintos, onde é possível observar que o retorno excedente médio no ano seguinte dos ganhos que foram realizados é $3,4 \%$ maior que o das perdas que não foram realizadas. Isso foi um ponto importante, pois mostrou que a hipótese das informações privilegiadas não era válida, ou seja, que investidores vendiam as ações com ganhos porque eles tinham informações privilegiadas que essas ações iriam cair e mantinham as ações perdedoras devido a informações secretas que iriam subir (Barberis e Xiong, 2009).

Outro ponto importante no estudo de Odean (1998) foi que considerações fiscais falharam em gerar mais informações acerca do efeito disposição. Como discutido anteriormente, tais considerações predizem uma maior propensão a vender ações com perdas porque a realização de tais perdas pode ser usada para compensar ganhos tributáveis com outras ações. Odean (1998) descobriu que somente em um mês específico do ano, no caso dezembro, a proporção das perdas realizadas excedia a proporção dos ganhos realizados. Isso sugere que efeitos fiscais somente têm uma importância crucial quando o final do ano fiscal se aproxima.

Um ano depois do estudo de Odean (1998), Barber e Odean (1999) realizaram outra bateria de testes analisando 162.948 transações de ações, durante o período de janeiro de 1987 a janeiro de 1993, de 10.000 contas de uma corretora, selecionadas aleatoriamente. É importante comentar que nesse estudo a base de dados inicial era a mesma do artigo publicado em 1998. Os autores novamente verificaram que o efeito disposição estava presente tanto para número como volume de transações. No caso do número de transações, a realização dos ganhos era 5 pontos percentuais mais frequentes do que a realização das perdas. 
Em 1999, Odean publicou também outro estudo utilizando novamente a mesma base de dados da corretora de varejo utilizada no estudo publicado em 1998 e reutilizada no estudo de 1999 com Barber. Entretanto, em Odean (1999) o objetivo era testar se o lucro obtido com transações no mercado acionário dos clientes desta corretora de varejo era suficientemente alto para compensar os custos de transação. Os resultados foram surpreendentes, segundo o próprio Odean (1999), porque em geral não só a diferença de retorno entre as ações compradas e vendidas não era positiva o suficiente para cobrir os custos de transação como era, na média das negociações, negativa. Esses altos custos de transação resultavam, segundo o autor, da excessiva negociação dos investidores. Duas explicações foram dadas para essas excessivas transações. Um motivo, já discutido anteriormente, seria o excesso de confiança dos investidores. Segundo Odean (1999) o excesso de confiança faz que as pessoas negociem mesmo quando os lucros esperados das transações não sejam altos o suficiente para cobrir os custos de transação, resultando em prejuízos. A outra causa das excessivas operações seria o efeito disposição. O autor constatou isso através da análise minuciosa da maneira como os investidores operavam no mercado. Odean (1999) observou os retornos das ações antes e depois das compras e vendas feitas pelos investidores e viu que eles tendiam a comprar aquelas ações que mais tinham subido ou caído nos seis meses anteriores em relação àquelas que eles vendiam. Além disso, ele constatou que eles vendiam ações que tinham subido, em média, muito rapidamente nas semanas recentes, além de venderem mais ações ganhadoras do que perdedoras.

Após a publicação dos resultados dos trabalhos de Odean, surgiram diversas outras investigações sobre a presença do efeito disposição no mercado de valores mobiliários, inclusive com bases bastante distintas, como foi o caso do estudo de Locke e Mann (2000) que utilizaram commodities da Bolsa de Mercadorias de Chicago. Este pode ser considerado um mercado para investidores mais qualificados, mas, mesmo assim, Locke e Mann (2000) concluíram que estes investidores também eram afetados pelo efeito disposição, já que tendiam a vender mais rapidamente seus ganhos e manter suas perdas por mais tempo.

Existem estudos que testam o efeito disposição fora do mercado americano. Como exemplos podemos citar Boebel e Taylor (2000), que testaram o efeito disposição na Nova Zelândia, Grinblatt e Keloharju (2001) que observaram o comportamento dos investidores no mercado finlandês, Shapira e Venezia (2001), que estudaram o mercado israelense, Barber et alii (2007) que analisaram o mercado de Taiwan e Choe e Eom (2009) que analisaram o mercado futuro na Coréia.

O estudo de Boebel e Taylor (2000) testou o efeito disposição na Nova Zelândia analisando 125 contas de uma grande corretora de varejo entre $1^{\circ}$ de junho de 1988 e 30 de abril de 1999. Segundo os autores, o estudo deles diferia do de Odean (1999) em alguns aspectos, mas os principais eram que na Nova Zelândia ganhos de capital não eram taxados e que os dados eram de uma corretora de varejo, que permitia aos investidores usufruir de aconselhamento profissional. O estudo foi conduzido usando duas medidas de determinação do preço de referência para se 
estabelecer se um investimento estava na área de ganhos ou perdas no momento da venda. Primeiro foi usado o preço médio de compra da ação e depois uma medida de força relativa para indicar o desempenho recente da ação. De uma maneira geral, os autores não conseguiram constatar o efeito disposição nos investidores neozelandeses. Isso foi mais claro quando o preço médio de compra foi usado como referência. Já no caso da medida de força relativa, os investidores exibiram uma leve tendência a demonstrar o efeito disposição, condicionada principalmente pelos investidores mais ativos na amostra, ou seja, que negociavam mais frequentemente. Entretanto essa tendência se dissipava quando a base de dados era expandida para incluir vendas adicionais, cujos preços de compra não eram conhecidos.

Grinblatt e Keloharju (2001) por sua vez analisaram as transações realizadas por investidores finlandeses entre final de dezembro de 1994 e começo de janeiro de 1997. Utilizando dados disponibilizados pela Central de Custódia Finlandesa, os autores comprovaram que existe uma resistência a vender ações com perdas no mercado finlandês. Utilizando regressões logísticas, os autores conseguiram isolar diferentes variáveis, como por exemplo, fazer a distinção do efeito disposição da estratégia contrária, controlando tanto os retornos históricos das ações como a proporção das perdas.

Shapira e Venezia (2001) analisaram o comportamento de investimento de um grande número de clientes de uma grande corretora em Israel em 1994. O objetivo principal do estudo era pesquisar as tomadas de decisão de investidores independentes, ou seja, que tomavam as decisões por conta própria assumindo o risco, e de investidores cujas contas eram administradas por profissionais de mercado. O objetivo era testar se o efeito disposição, que na maior parte dos estudos até então tinha sido comprovado para investidores individuais nos EUA, também se aplicava a investidores profissionais. O estudo comprovou que o efeito disposição era presente tanto no grupo de investidores individuais como profissionais, sendo que era mais intenso no grupo dos investidores profissionais. Um segundo objetivo do estudo foi tentar comparar frequência de negociação, volume e lucro entre os dois grupos de investidores, procurando explicar também melhor as diferenças entre o comportamento deles. Os autores descobriram que, apesar do grupo dos investidores profissionais terem uma maior atividade de negociação, eles diversificavam mais, tinham uma menor correlação de sua carteira com o mercado, além de obter um maior lucro. Segundo os autores isso seria, pelo menos em parte, uma prova que eles estariam menos sujeitos aos vieses cognitivos que os investidores independentes.

O estudo de Barber et alii (2007) analisou todas as transações efetuadas na Bolsa de Taiwan entre 1995 e 1999 para testar se o efeito disposição conseguia ser detectado naquele mercado. Os autores testaram o efeito disposição tanto para os investidores como um todo, que eles definiram como investidor agregado, como para grupos de investidores individuais. No investidor agregado, os testes demonstraram que os investidores em Taiwan tinham uma probabilidade duas vezes maior 
de vender uma ação com ganho do que uma com perda. Além do mais, $85 \%$ dos investidores em Taiwan vendiam ações ganhadoras com uma velocidade maior do que aquelas perdedoras.

Os autores também dividiram os investidores em 5 grupos: indivíduos, empresas, fundos mútuos domésticos, investidores estrangeiros e operadores do mercado. Enquanto que investidores individuais, empresas e operadores do mercado eram relutantes em realizar perdas, ou seja, mais propensos a exibir o efeito disposição, fundos mútuos domésticos e investidores estrangeiros (que representavam menos de 5\% de participação no mercado em termos de valor) não exibiam tal característica.

Outro resultado interessante do estudo de Barber et alii (2007) na Bolsa de Taiwan foi que investidores com posições vendidas eram também relutantes a realizar perdas, ou seja, exibiam comportamento similar a investidores com posições compradas. É importante reparar que, ao contrário dos investidores com posições compradas, no caso de investidores com posições vendidas, a relutância em realizar perdas implica em não comprar a respectiva ação para fechar sua posição em decorrência de uma subida de preço.

Além desses resultados, os autores não descobriram haver diferenças significativas no efeito disposição entre homens e mulheres. Isso foi interessante, porque apesar dos autores terem constatado como Barber e Odean (2001) que homens transacionavam mais do que as mulheres, homens e mulheres exibiam uma relutância parecida em realizar perdas. O estudo de Choe e Eom (2009) realizado com investidores na Coréia é interessante porque testou o efeito disposição abordando o mercado futuro e não o mercado à vista. Usando dados extraídos do índice da Bolsa Futura na Coréia (KOSPI) entre início de janeiro de 2003 e final de março de 2005, os autores descobriram fortes evidências do efeito disposição neste mercado, além de uma forte ligação da intensidade deste efeito com o tipo de investidor Os autores constataram que investidores individuais eram mais suscetíveis ao efeito disposição que investidores institucionais e estrangeiros. Além disso, a experiência do investidor tende a diminuir a exposição ao efeito disposição. Outro ponto interessante desvendado pelos autores era que o efeito disposição se mostrava mais forte em posições compradas que vendidas. Por fim foi encontrada uma relação inversa entre a intensidade do efeito disposição e o desempenho do investidor, mostrando que tal viés é prejudicial à boa prática de investimentos.

Dentre os estudos brasileiros sobre o efeito disposição, destacam-se os trabalhos de Da Costa Jr. et alii (2008), Accorsi et alii (2007), Karsten (2005), Mineto (2005) e Macedo Jr. (2003).

O trabalho de Da Costa Jr. et alii (2008) analisou com base em um experimento como o efeito disposição afetava indivíduos com e sem experiência no mercado acionário. Foi realizado um experimento de laboratório com o auxílio de um programa computacional que simulava um mercado de ações exógeno. A simulação foi aplicada a três grupos distintos de pessoas. Enquanto o primeiro grupo foi formado por 33 indivíduos com diferentes níveis de experiência na com- 
pra e venda de ações em bolsa de valores, o segundo foi constituído por 44 alunos de graduação de uma universidade pública, sem nenhuma experiência na área financeira. Por fim o terceiro grupo foi formado por 50 simulações onde as decisões de compra e venda foram geradas de forma aleatória, servindo como controle do experimento. Ao todo foram analisadas 7.429 operações, onde se verificou que a maioria dos indivíduos foi afetada pelo efeito disposição. Entretanto, como era de se esperar, foi encontrada uma relação inversa entre experiência prévia do participante e suscetibilidade ao efeito disposição. Accorsi et alii (2007) testaram diversos vieses cognitivos, incluindo o efeito disposição, usando um programa de simulação de investimentos via internet. Além do efeito disposição foram testados o efeito doação, o medo do arrependimento e a influência da forma de apresentação do problema ("framing effect"). O efeito doação no estudo foi caracterizado como a influência sofrida pelos investidores que recebiam uma carteira por doação, pois normalmente definem suas expectativas de ganhos de acordo com a rentabilidade futura da carteira recebida e não pela rentabilidade futura do mercado. A pesquisa foi feita com 51 diretores de empresas matriculados em um curso de MBA local, com suposto maior conhecimento de mercados financeiros, e com 218 médicos. Os resultados foram interessantes, a começar pelo efeito disposição que não foi detectado em nenhum dos dois grupos de participantes. O efeito doação só afetou os médicos, indicando que investidores com melhor conhecimento de mercado são menos vulneráveis a essa anomalia. O medo do arrependimento só afetou os alunos de MBA, o que pode ser explicado pelo fato desses sujeitos ao terem um melhor conhecimento de mercado financeiro, possuam no seu subconsciente um maior grau de exigência consigo mesmos ao cometerem erros. Por fim a influência da forma afetou os dois grupos, mostrando que essa anomalia independe do grau de conhecimento e convívio com o mercado financeiro. Em sua dissertação de mestrado, Karsten (2005) analisou a incidência do efeito disposição em um grande número de investidores na BOVESPA, entre pessoas físicas, pessoas jurídicas institucionais e não-institucionais. A base de dados foi uma amostra aleatória de 12.000 investidores fornecidos gratuitamente pela BOVESPA, que fizeram transações no período de 2001 a 2004. Usando várias medidas do efeito disposição em corte transversal, o autor constatou que os investidores como um todo tendem a realizar ganhos mais cedo que perdas ao longo de todo o período analisado assim como para cada ano. Entretanto, quando o efeito disposição foi testado por tipo de investidor, somente os investidores pessoa física demonstraram exibir tal comportamento, ao passo que não foi possível chegar a resultados conclusivos para os demais investidores. 
Em uma segunda análise, Karsten (2005) usou uma medida em séries temporais para testar o efeito disposição, que foi encontrado em todos os anos e para todos os investidores, com exceção dos investidores institucionais no ano de 2004 e utilizando valores em Reais ao invés de quantidade de transações com ganhos ou perdas.

Por fim, para validar os resultados obtidos anteriormente, o autor aplicou testes complementares comparando os resultados após isolar alguns fatores como: vendas motivadas pela tributação, rebalanceamento de carteiras, dividendos e a influência da variação de preço de três ações com liquidez que sofreram quedas bruscas no período analisado. Entretanto, nenhum destes fatores alterou a tendência a realizar ganhos mais cedo que perdas.

O trabalho de Macedo Jr. (2003) testou o efeito disposição e o efeito doação. Durante o estudo, os efeitos disposição e doação foram testados por intermédio de uma simulação de investimentos realizada com 226 estudantes de quatro Universidades distintas. A vantagem da simulação promovida por Macedo Jr. (2003) é que puderam ser isolados os motivos para a negociação de ações que não estivessem relacionados com a vontade de comprar ou vender dos participantes (como a pressão no orçamento, por exemplo). O efeito disposição foi comprovado, visto que os participantes tenderam a liquidar mais rapidamente os seus investimentos ganhadores numa proporção até $25 \%$ maior que a realização das suas perdas. Mineto (2005), por sua vez, testou o efeito disposição, definido como a diferenciação da percepção ao risco quando a decisão de escolha envolve ganhos ou perdas, tendo em vista um ponto de referência. O teste foi aplicado por intermédio de uma pesquisa experimental envolvendo a tomada de decisão sob condições de incerteza e risco na compra e venda de ações. Ao venderem mais rapidamente os ativos que apresentaram ganhos, comparativamente aos ativos que apresentaram perdas, os investidores demonstram aversão ao risco no campo dos ganhos e propensão ao risco no campo das perdas, indo de acordo com a Teoria do Prospecto.

O experimento de Mineto (2005) foi realizado de forma similar ao aplicado por Macedo Jr. (2003), utilizando uma amostra composta por 176 estudantes universitários (95 mulheres e 81 homens) e simulando decisões financeiras em ambiente de sala de aula. Os resultados obtidos por Mineto (2005) mostram que a intensidade do efeito disposição depende do sexo dos investidores e do ponto de referência a partir do qual os ganhos e as perdas são computados. A primeira hipótese de que os investidores vendem mais ativos quando o preço de venda é superior ao preço de compra do que quando o preço de venda é inferior ao preço de compra foi aceita com alto grau de significância estatística $(Z=9,66)$ revelando que $66 \%$ das transações foram realizadas no campo dos ganhos e $30 \%$ no campo das perdas.

Quando o preço de compra foi substituído pelo preço do período anterior como preço de referência, os resultados foram mantidos, embora com menor significância estatística $(Z=5,40)$. Quando as análises foram feitas separadamente para o grupo de homens e de mulheres, revelaram resultados de mesma intensi- 
dade para ambos grupos, no caso da utilização do preço de compra como preço de referência. Porém, quando o preço de referência foi substituído pelo preço anterior, o grupo de mulheres mostrou-se favorável às vendas dos ativos com perdas, indicando que o efeito disposição não está presente no referido grupo quando a referência é o preço prévio anterior. Assim, a hipótese de que a variável sexo influi no comportamento do investidor, foi aceita.

\section{Metodologia}

Os dados sobre as composições das carteiras dos fundos de investimento foram obtidos junto à Comissão de Valores Mobiliários para o período compreendido entre novembro de 2003 e fevereiro de 2008. Foram solicitadas apenas as carteiras dos fundos de investimento em ações, e destas carteiras foram mantidos apenas as ações ou títulos representativos de ações, que são os valores mobiliários foco do presente artigo. Além disso, foram descartados os fundos de investimento em cotas para que não houvesse duplicidade de contagem dos fundos e de seus respectivos patrimônios.

A obrigatoriedade de informar mensalmente a composição das carteiras dos fundos de investimento está prevista na Instrução CVM no 302/99. Não foi possível obter dados de períodos anteriores porque as carteiras eram enviadas de forma documental até o ano de 2003. A partir daí, surgiu a opção de envio eletrônico destas informações, porém, o banco de dados passa a ser representativo na data inicial do estudo, ou seja, novembro de 2003.

As cotações históricas, sem ajuste, das ações foram solicitadas e adquiridas junto à Bolsa de Valores de São Paulo (BOVESPA) para o período compreendido entre 01.01.2003 e 30.04.2008. Embora diversos sistemas forneçam cotações históricas ajustadas, foi necessário obter uma base sem ajustes para viabilizar o estudo, já que as carteiras dos fundos de investimento são obtidas pela informação da época de envio das carteiras, ou seja, sem qualquer ajuste por bonificações, desdobramentos etc. As informações sobre os desdobramentos, agrupamento, bonificações e demais ajustes das ações foram obtidos junto à base do Economática. Essas informações foram fundamentais para ajustar as bases de posições dos fundos de investimento (todas sem ajustes) já que o aumento de uma ação específica pode estar relacionado, por exemplo, a um desdobramento em vez da compra líquida daquela ação. As composições das carteiras teóricas do IBrX-50 também foram solicitadas e obtidas junto à Bolsa de Valores de São Paulo para o período de 2003 a 2008.

O presente artigo busca testar se os fundos de investimento em ações vendem suas ações ganhadoras rapidamente e mantêm suas ações perdedoras por mais tempo. Se partirmos do pressuposto de que os investidores são indiferentes entre venderem seus ganhos ou perdas, ou seja, não estão sujeitos ao efeito disposição, então, num mercado de alta, haverá mais ações com ganhos disponíveis para a venda e eles tenderão a vender mais ações vitoriosas, embora sejam indiferentes em fazer isso. Como consequência, para testar se os investidores estão dispostos 
a vender ganhos e manter prejuízos, é necessário identificar a frequência com que os ganhos e perdas são vendidos em relação às suas respectivas oportunidades de serem realizados.

Inicialmente foram trabalhados os dados das carteiras teóricas do IBrX-50. Com o intuito de conferir robustez ao estudo, somente foram consideradas as ações que integraram o referido índice no período de análise, já que estas representam as ações com maior liquidez e capitalização de mercado, já que, conforme definido anteriormente, o índice IBrX-50 é composto pelos 50 papéis mais líquidos da BOVESPA (BMFBOVESPA, 2010). Neste caso, as carteiras teóricas se referem neste trabalho à composição do IBrX-50 durante todo o período em análise. A definição do IBrX-50 já foi feita de maneira sucinta anteriormente, mas cabe aqui uma descrição mais detalhada dos critérios de inclusão de uma ação no índice, ou seja o detalhamento da composição das carteiras teóricas.

A carteira teórica do índice IBrX-50 tem vigência de quatro meses, sendo que vigora para os períodos de janeiro a abril, maio a agosto e setembro a dezembro. Ao final de cada quatro meses a carteira é reavaliada, segundo os seguintes critérios (BMFBOVESPA, 2010):

a) ser uma das 50 ações com maior índice de liquidez apurado nos doze meses antecedentes à reavaliação;

b) ter sido negociada no mínimo em $80 \%$ dos pregões ocorridos nos doze meses anteriores à formação da carteira.

É importante ter em mente neste estágio da metodologia, que o índice IBrX50 é altamente representativo do mercado acionário brasileiro, conforme mostra a figura 1, onde podemos ver a relação entre o valor de mercado das empresas que compõe o IBrX-50 e o valor de mercado de todas as empresas listadas na Bolsa de São Paulo.

Conforme se pode ver na figura 1, as empresas que compõe o IBrX-50 representam em média 70,30\% do valor de mercado de todas as empresas negociadas na Bolsa de São Paulo no período que vai de janeiro de 2007 a janeiro de 2010, ou seja, o índice IBrX-50 é altamente representativo para o mercado acionário brasileiro.

Na figura 2 podemos ver alguma estatísticas referentes à BMFBOVESPA. Segundo dados retirados da Federação Internacional das Bolsas, em dezembro de 2009 a BMFBOVESPA ocupava o nono lugar segundo o critério de capitalização de mercado em dólares, à frente de bolsas importantes, como da Alemanha e Espanhaou seja, uma posição relativamente forte. Com base nesses dados estatísticos, é de se esperar, portanto, em um primeiro estágio, que nossa base de dados seja bem representativa como ponto de referência para se analisar o efeito disposição e, obviamente com muita prudência, para se generalizar parcialmente os resultados. 


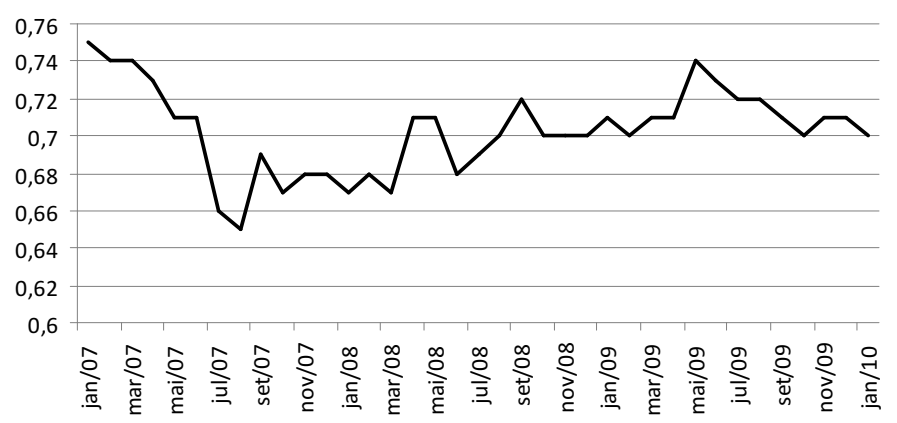

Fonte: BMFBOVESPA (Cálculos dos Autores)

Figura 1

Percentual dos valor de mercado das empresas que compõe o IBrX-50 no valor total de mercado da BMFBOVESPA

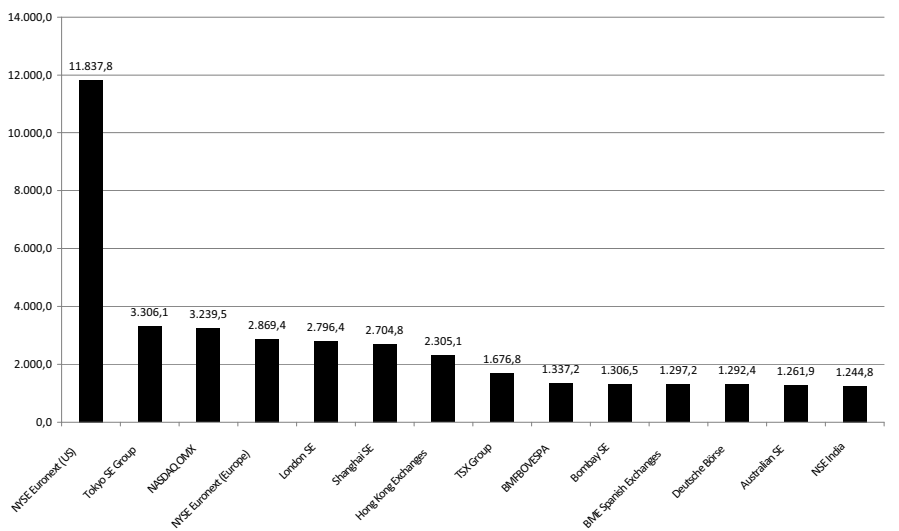

Figura 2

As maiores bolsas no mundo por capitalização de mercado (US\$ bi) (Dezembro 2010)

Em um segundo estágio, a partir da contabilização de todas as empresas que compunham o IBrX-50 no período de análise do estudo, ou seja, de novembro de 2003 e março de 2008, uma nova delimitação foi inserida para evitar distorções nos resultados tais como entrada ou saída do índice, seja por não atendimento dos critérios de inclusão, seja por fusões e aquisições. Promoveu-se então uma análise das carteiras teóricas mensais do $\mathrm{IBrX}-50$ com o intuito de direcionar o estudo às ações que integraram o referido índice durante todo o período sob análise. Assim, foram mantidas para análise apenas as 28 ações que integraram a carteira teórica do IBrX-50 em todos os meses sob análise. A lista dos códigos das 28 
ações usadas neste trabalho se encontra no apêndice. Vale a pena salientar, que entre essas 28 ações estão aquelas responsáveis pelo maior volume de negociação dentro da BOVESPA, como PETR3, PETR4, VALE3 e VALE5. A figura abaixo mostra qual foi o percentual individual dessas 28 ações no volume total negociado na BMFBOVESPA em 2009. Apesar de a nossa amostra ter sido colhido em anos anteriores, a soma total do percentual da nossa amostra no volume total de negociação da BMFBOVESPA em 2009 foi de 52,23\%, ou seja, as ações utilizadas neste estudo podem ser consideradas relativamente representativas do mercado.

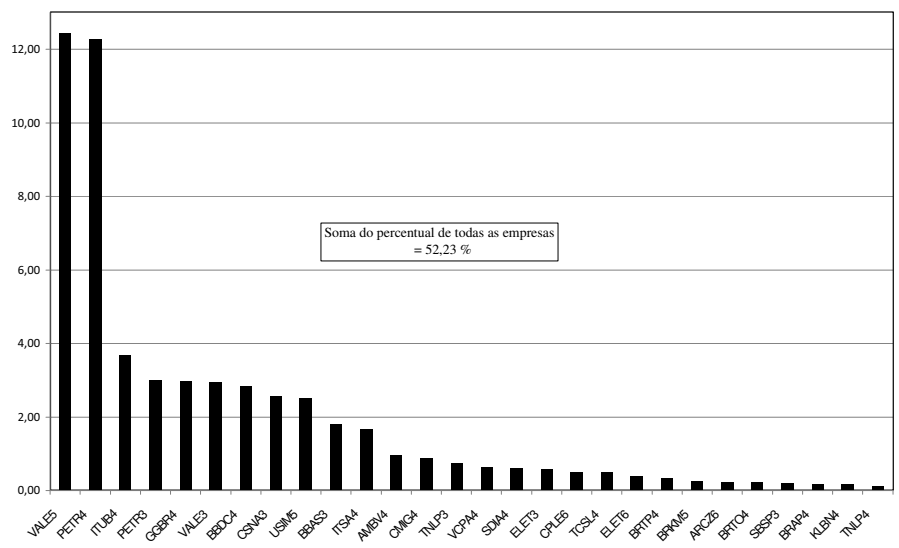

Figura 3

Percentual de cada ação no volume total de negociação na BMFBOVESPA em 2009

Uma vez delimitadas as ações, passou-se a trabalhar com os dados das carteiras dos fundos de investimento. Com o auxílio dos sistemas ACL e ACCESS, foram excluídas as ações pertencentes às carteiras dos fundos, mas que não fazem parte do grupo de 28 ações selecionadas para o presente artigo. O arquivo com as informações das carteiras dos fundos de investimento em ações possui apenas duas informações sobre data: a dada e hora de envio, além da data base da carteira. Assim, foi necessário incluir na base de dados a data do último dia de pregão de cada mês dentro do período sob análise, para que fosse possível encontrar o preço médio dos ativos na data da informação. O preço médio não ajustado na data da informação das carteiras é fundamental, visto que a base de dados também não apresenta a quantidade de ações detidas pelos fundos, mas apenas o montante financeiro das mesmas. Por conseguinte, foi necessário acessar a base de cotações sem ajustes para que fosse calculada a quantidade de ações detidas em cada período, informação esta imprescindível para cálculo dos preços de referência, bem como dos ganhos e perdas de capital não-realizados.

A base de cotações históricas sem ajuste foi importada para o EXCEL com auxílio do layout fornecido pela Bolsa de Valores de São Paulo. Esta base também 
foi filtrada para conter as cotações diárias apenas dos ativos que serão analisados neste artigo, no período de novembro de 2003 a fevereiro de 2008. A partir daí, os preços médios do último pregão de cada mês foram transportados para a planilha que contém as carteiras dos fundos de investimento. Assim, foi possível calcular as quantidades de ações detidas pelos fundos em cada período simplesmente dividindo o montante financeiro (informado pelos fundos de investimento) investido na ação pelo preço médio ${ }^{1}$ do último pregão de cada mês.

O próximo passo constituiu-se no cálculo do preço de referência. Esta medida é fundamental para a análise empírica promovida neste artigo, já que é utilizada para identificar se, numa data qualquer, os fundos de investimento possuem ganhos ou perdas de capital ainda não-realizados, ou se suas alienações geraram ganhos ou perdas. Isso porque na hora de ser avaliar de houveram ganhos ou perdas, independente de terem sido realizados ou não, é o preço de referência que serve de base de comparação. O ponto de referência é, portanto relevante porque cada investidor, seja ele experiente ou não, terá a sua própria referência para determinar se o ativo está no domínio do lucro ou do prejuízo e assim, tomar uma decisão sobre o investimento (Karsten, 2005).

Para o cálculo do preço de referência será utilizada a base de cotações históricas, definida anteriormente, com movimentações líquidas de cada ação e cada fundo, além de seu custo base. O preço de referência foi computado da seguinte forma:

$$
P R_{t}=Q_{t}^{-1}\left\{M A X\left[0, Q_{t}-Q_{t-1}\right] P_{t}+\operatorname{MIN}\left[0, Q_{t}-Q_{t-1}\right] P R_{t-1}\right\}
$$

onde:

$P R_{t}$ é o preço de referência, de um ativo qualquer, na data $t$;

$Q_{t}$ é a quantidade de ações, de um ativo qualquer, detida na data $t$;

$Q_{t-1}$ é a quantidade de ações, de um ativo qualquer, detida no período anterior.

$P_{t}$ é o preço médio do ativo na data $t ;^{2} \mathrm{e}$

$P R_{0}=P_{0}$.

Um dos motivos que levaram a utilização do preço médio para cálculo do preço de referência é o fato do preço médio ter sido a medida de valoração dos ativos de renda variável utilizado pelos fundos de investimento desde 14 de abril de 1970 (a partir da Resolução CMN n ${ }^{0}$ 145) até 20 de maio de 2008 (com a publicação da Instrução CVM no 465).

Naturalmente, a utilização da equação (1) pode gerar algum viés nos resultados, uma vez que no início do período amostral ele é uma aproximação e traz pouca acuracidade ao preço de referência, já que $P R_{0}=P_{0}$. Isso acontece porque

\footnotetext{
${ }^{1}$ Os preços médios são utilizados para fins de demonstração do patrimônio dos fundos de investimento.

${ }^{2}$ Uma vez que o tempo é medido em meses e a data base é o último pregão do mês, o preço médio refere-se, na maior parte deste trabalho, ao preço médio praticado no último dia de pregão do mês, salvo quando for feita menção diversa.
} 
o preço de aquisição dos ativos, pelos fundos de investimento, antes da data 0 não é conhecido, já que os mesmos não têm a obrigatoriedade de informá-lo à Comissão de Valores Mobiliários. Com o passar do tempo e o giro das carteiras, o preço de referência tende ao preço médio de aquisição, fortalecendo os resultados.

Como esse artigo é baseado na metodologia adotada por Odean (1998) e ele menciona que os resultados de seu trabalho são essencialmente os mesmos quando o preço de referência é calculado com base no preço médio, maior preço de compra, primeiro preço de compra ou preço de compra mais recente, a utilização do preço médio como preço de referência neste artigo encontra um bom respaldo científico. Além do mais, o preço médio dos ativos é bastante utilizado pelos próprios fundos de investimento para valoração de seus patrimônios diários e participação de cotistas.

Seguindo a metodologia de Odean (1998), mensalmente os estoques ajustados de cada ativo detido pelos fundos são então comparados com o período anterior e, com isso, são identificadas as vendas líquidas no período para cada fundo de investimento. Em seguida, o preço de venda ${ }^{3}$ de um ativo detido por um fundo específico é comparado com o seu respectivo preço referencial, calculado com base na equação (1), para identificar se aquela ação foi vendida com lucro ou prejuízo. Quando uma ação é vendida e o preço de venda é maior que o preço referencial, ela é considerada um ganho realizado. De forma similar, quando uma ação é vendida e o preço de venda é menor que o preço referencial, ela é considerada uma perda realizada.

Baseando-se ainda na metodologia de Odean (1998), cada ação que estava na carteira de um fundo no período anterior e não foi vendida é considerada como um ganho ou uma perda não-realizada. Os ganhos ou perdas não-realizados são determinados pela comparação entre o preço médio do último dia útil do período atual e seu preço de referência no período anterior. Se o preço de referência é maior que o preço médio atual, ela é considerada uma perda não-realizada; se o preço de referência é menor que o preço médio atual, ela é considerada um ganho não-realizado.

Em seu trabalho, Odean (1998) cita um exemplo que podemos usar para esclarecer um pouco mais os conceitos. Vamos supor que um fundo de investimento (A) possua 5 ações em sua carteira, A1, A2, A3, A4 e A5, sendo que A1 e A2 estão valendo mais do que foi investido nelas e A3, A4 e A5 estão valendo menos, individualmente. Similarmente, outro fundo de investimento (B) possui 3 ações em sua carteira, B1, B2 e B3, sendo que B1 e B2 estão valendo mais do que foi pago, enquanto B3 está valendo menos. Se o fundo A vende A1 e A3 e o fundo B vende B1, as vendas de A1 e B1 são consideradas ganhos realizados, enquanto a venda de A3 é considerada uma perda realizada.

As demais ações são consideradas ganhos ou perdas não-realizadas. Uma vez que A2 e B2 poderiam ter sido vendidas com lucro e não foram, elas são con-

${ }^{3} \mathrm{O}$ preço de venda adotado corresponde ao preço médio na data do relatório de composição de carteiras enviado pelos fundos de investimento à CVM. 
sideradas ganhos não-realizados. De forma similar, A4, A5 e B3 são consideradas perdas não-realizadas. Assim, para os dois fundos em conjunto, foram contados 2 ganhos realizados, 1 perda realizada, 2 ganhos não realizados e 3 perdas não-realizadas.Ganhos e perdas realizadas e não-realizadas são somados para cada fundo de investimento e entre os fundos de investimento e então são calculadas as proporções de ganhos realizados (PGR) e as proporções de perdas realizadas (PPR), conforme as seguintes fórmulas:

$$
\begin{aligned}
& P G R=\frac{G R}{(G R+G N R)} \\
& P P R=\frac{P R}{(P R+P N R)}
\end{aligned}
$$

onde:

$G R$ são os ganhos realizados;

$G N R$ os ganhos não-realizados;

$P R$ as perdas realizadas; e

$P N R$ as perdas não-realizadas.

Continuando com o exemplo desenvolvido por Odean (1998), se utilizarmos as equações (2) e (3) para calcularmos $P G R$ e $P P R$ com base no exemplo dos parágrafos anteriores, encontraremos $P G R=1 / 2$ e $P P R=1 / 4$. Uma grande diferença entre a proporção de ganhos realizados $(P G R)$ e a proporção de perdas realizadas $(P P R)$ indica que investidores estão mais dispostos a realizar ganhos ou perdas.

O passo seguinte então foi calcular $P G R$ e $P P R$ para a base analisada. Este cálculo foi promovido tanto em termos de transações quanto em relação ao volume negociado individualmente pelos fundos. Neste momento foi necessário aplicar outro filtro, que comparou os ganhos realizados (numa ação qualquer de um fundo específico) com o montante financeiro detido no período imediatamente anterior. Aquelas ações cujos lucros realizados no período superaram o montante financeiro detido no período anterior foram analisadas e reajustadas (quando detectado problema de ajuste por bonificação ou desdobramento) ou retiradas da base de dados (quando detectada falha na informação fornecida por parte do fundo de investimento).

Conforme discutido anteriormente, a especificação de um ponto de referência a partir do qual os ganhos e as perdas são determinados, conforme visto na equação (1), assim como a determinação das proporções de ganhos e perdas realizadas, de acordo com as equações (2) e (3), são fundamentais para se testar a hipótese do efeito disposição de que os investidores vendem ganhos mais rapidamente que as perdas.

Karsten (2005) argumenta de forma clara essa importância do cálculo da razão da Proporção dos Ganhos Realizados $(P G R)$ e da Proporção das Perdas Realizadas $(P P R)$. Segundo o autor, para se testar o efeito disposição, não podemos simplesmente comparar em termos absolutos se os investidores venderam mais 
ações com ganhos do que com perdas. Isto certamente iria conduzir a resultados equivocados, dependendo do viés do mercado. Ao invés disto, é mais confiável analisamos a frequência com a qual eles vendem ações ganhadoras e perdedoras relativo à oportunidade de vender em cada um dos dois tipos de situação, ou seja, com ganhos ou perdas.

Baseado nessa discussão e seguindo a metodologia adotada por Odean (1998), o passo seguinte é descrever a hipótese nula do trabalho, assim como explicitar melhor o cálculo da estatística de teste. No caso de não haver o efeito disposição, ou seja, a tendência de vender mais ações ganhadoras que perdedoras em relação à oportunidade de vender ambas - ganhadoras e perdedoras, a Proporção de Ganhos Realizados (PGR) deveria ser menor ou igual à Proporção de Perdas Realizadas $(P P R)$. O teste para verificar a presença do efeito disposição é, portanto formulado como testando a hipótese nula de que a Proporção de Ganhos Realizados $(P G R)$ ser menor ou igual à Proporção de Perdas Realizadas $(P P R)$ :

$$
\begin{aligned}
& H_{0}=P G R \leq P P R \\
& H_{a}=P G R>P P R
\end{aligned}
$$

Se a hipótese nula for rejeitada, isso significa que podemos confirmar o efeito disposição, ou seja, que investidores preferem vender mais ações vencedoras que perdedoras em relação às oportunidades de venderem ambas.

De uma maneira formal o teste estatístico adequado para se comparar a magnitude entre as duas variáveis descritas acima $(P G R$ e $P P R)$ é o teste $t$ para duas proporções amostrais (Da Costa Jr. et alii, 2008). Este é definido da seguinte maneira:

$$
t=\frac{P G R-P P R}{E P(P G R-P P R)}
$$

onde $E P$ é o erro padrão da diferença entre as proporções $P G R$ e $P P R$, que é dado por:

$$
E P=\sqrt{\frac{P G R(1-P G R)}{G R+G N R}+\frac{P P R(1-P P R)}{P R+P N R}}
$$

Após calcular o efeito disposição para os Fundos de Investimento em Ações em geral, decidiu-se, em um segundo estágio, fazer uma segmentação entre fundos de varejo e fundos destinados a investidores qualificados e testar se o efeito disposição se manifestava de maneira diferente nesses fundos. Isso se deve ao fato que, embora a base de fundos de investimento utilizada para realização do teste do efeito disposição já estivesse segmentada para contemplar apenas os Fundos de Investimento em Ações, esta classe ainda admite uma divisão por duas categorias: fundos destinados a investidores qualificados e fundos de varejo. 
De acordo com os dados fornecidos pela Comissão de Valores Mobiliários, existiam no ano de 2007, 700 fundos de investimento em Ações (desconsiderandose os fundos de investimento em Cotas de fundos de investimento em Ações), sendo 390 (56\%) destinados a investidores qualificados e 310 fundos de varejo. Em termos de patrimônio líquido, os fundos qualificados detinham, na mesma época, R\$ 101,5 bi, enquanto os fundos de varejo geriam $\mathrm{R} \$ 64,3$ bi (39\% do patrimônio líquido dos Fundos de Investimento em Ações).

Considerando-se que os fundos qualificados são destinados àqueles investidores mais sofisticados, experientes e cientes dos riscos envolvidos em transações no mercado de valores mobiliários, pode ser que haja alguma distinção na gestão dos recursos destes fundos em relação àqueles que aceitam gerir os recursos de qualquer investidor, por menos informado que este investidor seja.

Com base nessa suposta diferenciação observada entre as categorias de Fundos de Investimentos em Ações, promoveu-se, portanto uma divisão da base de dados, separando-se os fundos de varejo daqueles destinados a investidores qualificados. Entretanto, a primeira dificuldade encontrada deveu-se ao fato da informação sobre a categoria do fundo de investimento ter sido incluída no sistema informatizado de recebimento de documentos da CVM apenas após a Instrução $n^{0} 409$, em agosto de 2004.

Assim, a solução encontrada foi segmentar os fundos a partir do momento em que a informação sobre a categoria do fundo estivesse disponível e replicar esta informação para os períodos anteriores. Aqueles fundos que foram criados e extintos antes da publicação da Instrução n ${ }^{\circ} 409$, ou seja, antes da informação sobre categoria estar disponível nos sistemas da CVM, foram excluídos da base de dados já que não era possível discriminá-los por segmento. A partir daí, uma nova série de cálculos foi executada, considerando separadamente as transações efetuadas pelos fundos de investimento em ações destinados a investidores qualificados e os fundos de varejo.

\section{Resultados}

Os testes iniciais foram feitos seguindo duas metodologias diferentes de apuração das proporções de ganhos e perdas realizadas, que foram definidos teste A e teste B. No teste A os cálculos foram feitos mensalmente considerando cada ação detida pela carteira de cada fundo, individualmente, para depois serem agregados para todo o período sob análise. Quando o cálculo é feito desta forma, cada mês é ponderado de acordo com a quantidade de transações e possíveis transações. Entretanto, adotar este critério pode fazer com que muito peso seja dado para meses atípicos, o que pode viesar os resultados. Isso poderia acontecer, por exemplo, num mês em que haja uma forte alta na taxa básica de juros não esperada pelo mercado, o que poderia acarretar uma forte realização de ganhos ou prejuízos, dependendo do movimento do mercado, enquanto a base de transações possíveis permaneceria a mesma (quantidade de ações detidas por todos fundos de investimentos analisados). 
Devido a esse possível viés, foi decidido realizar uma segunda metodologia de contagem diferente, que definimos teste B. Neste caso, calculamos as proporções de ganhos e perdas realizadas com base na média mensal de tais proporções, fazendo com que cada mês tivesse a mesma relevância nos cálculos, reduzindo assim o impacto que meses atípicos pudessem gerar nos resultados dos testes. ${ }^{4}$

O teste A e o teste B foram baseados nas transações efetuadas e possíveis, ou seja, as transações foram consideradas por ativo e por fundo individualmente. Neste caso, se uma ação do fundo A for vendida, ela é considerada um ganho ou perda realizada. Por outro lado, as ações que permanecem inalteradas ou não são vendidas são consideradas, individualmente, como um ganho ou perda nãorealizada.

Na tabela 1 podemos ver os resultados dos testes A e B descritos anteriormente. $\mathrm{O}$ primeiro resultado (teste A) mostra que a hipótese nula descrita na fórmula (4) não pode ser rejeitada a um grau de significância de $95 \%$ (estatística $t=0,94$ ), ou seja, não é possível constatar o efeito disposição. A magnitude da diferença entre $P G R$ e $P P R$ é de apenas $0,21 \%$, já que $\mathrm{PGR}=49,16 \%$ e PPR $=48,94 \%$.

Já no teste $\mathrm{B}$, a hipótese nula é rejeitada (confirmação do efeito disposição), mas com baixo grau de significância estatística, quando comparado, por exemplo, ao estudo de Odean (1998). Conforme se pode observar na tabela 1, o teste monocaudal da hipótese nula é rejeitado com uma estatística t de 6,38, enquanto nos testes iniciais de Odean (1998) a mesma hipótese é rejeitada com uma estatística t maior que 35. A magnitude da diferença entre $P G R$ e $P P R$ também foi menor neste teste quando comparada com estudos prévios. A diferença encontrada, conforme mostra a tabela 1 (teste B), foi de apenas 1,43 pontos percentuais, já que $\mathrm{PGR}=49,30 \%$ e PPR $=47,87 \%$.

Tabela 1

Teste estatístico do efeito disposição por transação (valores agregados)

\begin{tabular}{ccccccccc}
\hline Teste & GNR+GR & PNR+PR & GR & PR & PGR & PPR & PGR-PPR & $t$ \\
\hline A & 168.160 & 69.918 & 82.660 & 34.221 & $49,16 \%$ & $48,94 \%$ & $0,21 \%$ & 0,94 \\
B & 168.160 & 69.918 & 82.660 & 34.221 & $49,30 \%$ & $47,87 \%$ & $1,43 \%$ & 6,38 \\
\hline
\end{tabular}

GNR+GR: Ganhos Não-Realizados + Ganhos Realizados; PNR+PR: Perdas Não-Realizadas + Perdas Realizadas; GR: Ganhos Realizados; PR: Perdas Realizadas; PGR: Proporção de Ganhos Realizados; PPR: Proporção de Perdas Realizadas; PGR-PPR: Proporção de Ganhos Realizados - Proporção de Perdas Realizadas; $t$ : Estatística $t$

Esses dois primeiros testes (A e B) consideraram cada venda com ganho, venda com perda, ganho não realizado e perda não realizada como observações independentes, separadas e de mesmo peso, qualquer que fosse o volume negociado em cada transação. Com relação à ponderação das transações, considerar cada

\footnotetext{
${ }^{4}$ É importante reparar que estaremos usando sempre esses procedimentos em todos os testes realizados neste trabalho, ou seja, as tabelas 2 a 6 em diante estarão sempre subdivididas em dois subtestes, onde o primeiro equivalerá ao A e o segundo ao B. Por exemplo, na tabela 2, o teste C equivale ao mesmo procedimento do teste $\mathrm{A}$, enquanto o teste $\mathrm{D}$ equivale ao $\mathrm{B}$, ou seja, no teste $\mathrm{D}$ as proporções de ganhos e perdas realizadas são calculadas com base na média mensal das proporções, eliminando os já discutidos vieses oriundos do teste $\mathrm{C}$.
} 
negócio com a mesma relevância, independente do volume transacionado, parece não representar a realidade e o comportamento dos fundos de investimento com boa precisão.

Um exemplo pode ajudar a elucidar melhor essa questão: Imagine que um determinado fundo de investimento possua uma carteira formada por 4 ações, $X$, Y, Z e W. Suponha, além disso, que o montante investido em cada ação seja igual e equivalente a R\$ 100 mil, e que X e Y estejam sendo negociadas com lucro, enquanto $\mathrm{Z}$ e W estejam sendo negociadas com prejuízo. Se o fundo necessitar vender R\$ 200 mil e faz isso por intermédio da alienação de $\mathrm{R}$ \$ 90 mil de cada ação com lucro (X e Y) e R \$ 10 mil de cada ação com prejuízo (Z e W), isso quer dizer que o fundo realizou muito mais de seus ganhos do que suas perdas.

Porém, os primeiros testes realizados (A e B) consideram que cada transação tem o mesmo peso, ou seja, no exemplo do parágrafo anterior, PGR e PPR seriam iguais a 1 , dificilmente mostrando o efeito disposição nos testes estatísticos. Com o intuito de registrarmos com mais fidelidade o comportamento dos fundos de investimento, podemos, de forma distinta, calcular PGR e PPR em termos de volume transacionado, o que mudaria o resultado do exemplo anterior para PGR = 0,9 e PPR $=0,1$.

Considerar o volume transacionado para calcular as proporções de ganhos e perdas realizadas parece então representar melhor a preferência dos fundos de investimento no momento em que fazem alienações, o que também contribui para eliminar ruídos como a venda de uma pequena posição de uma ação qualquer para completar o valor de uma solicitação de resgate, que não pode ser feita com a venda de outra posição qualquer.

Assim, uma nova bateria de cálculos foi promovida, considerando o volume financeiro detido pelos fundos de investimento em cada ação de suas carteiras. Mensalmente, foram calculados os volumes financeiros dos ganhos realizados, perdas realizadas, ganhos não-realizados e perdas não-realizadas, e esses montantes foram acumulados ao longo do período sob análise. Na tabela 2 são mostrados os resultados dos testes do efeito disposição por volume. Os testes por volume seguiram a mesma linha de raciocínio dos testes iniciais do efeito disposição por transação: Assim como no caso dos testes A e B do efeito disposição por transação, no caso dos testes por volume também foram feitos dois testes $\mathrm{C}$ e $\mathrm{D}$, que seguiram a mesma metodologia de cálculo dos testes $\mathrm{A}$ e $\mathrm{B}$. O teste $\mathrm{C}$ equivale ao teste A da tabela 1, onde os cálculos foram feitos mensalmente considerando cada ação detida pela carteira de cada fundo, individualmente, para depois serem agregados para todo o período sob análise. Por sua vez o teste $\mathrm{D}$ equivale ao B, onde as proporções de ganhos e perdas realizadas foram calculadas com base na média mensal de tais proporções, para eliminar os eventuais vieses oriundos da contabilização individual de cada ação.

Conforme podemos observar na tabela 2, quando testamos o efeito disposição por volume não é possível identificá-lo, tanto pelo teste $\mathrm{C}$ quanto pelo $\mathrm{D}$. No teste C a Proporção de Ganhos Realizados $(5,68 \%)$ é 3,76\% menor que a Proporção 
das Perdas Realizadas $(9,44 \%)$. Mesmo quando desconsiderada a atipicidade de cada mês, conforme mencionado anteriormente, e calculando-se a média mensal de PGR e PPR (teste D), ainda não é possível identificar o efeito disposição nos fundos de investimento, já que PGR $=6,33 \%$ e PPR $=8,94 \%$, mostrando que os fundos de investimento analisados tendem a vender mais rapidamente suas perdas em vez de seus ganhos.

Tabela 2

Teste estatístico do efeito disposição por volume (valores agregados)

\begin{tabular}{ccccccc}
\hline Teste & GNR+GR & PNR+PR & GR & PR & GR(\%) & PR(\%) \\
\hline C & 241.371 .823 .342 & 20.820 .857 .894 & 13.698 .959 .518 & 1.964 .652 .542 & $5,68 \%$ & $9,44 \%$ \\
D & 241.371 .823 .342 & 20.820 .857 .894 & 13.698 .959 .518 & 1.964 .652 .542 & $6,33 \%$ & $8,94 \%$ \\
\hline
\end{tabular}

Confrontando-se as tabelas 1 e 2 é possível identificar que os fundos de investimento em ações tendem a fazer transações mais volumosas com ativos que estão sendo negociados com perdas de capital não-realizadas. Se, por um lado, os fundos realizam mais negócios com ações que possuem ganhos não-realizados em detrimento das ações com perdas não- realizadas (conforme mostra a tabela 1), por outro lado, estes mesmos fundos negociam um volume significativamente maior de ações que possuem perdas de capitais não-realizadas (tabela 2).

Conforme descrito anteriormente na metodologia, após estimar o efeito disposição para os Fundos de Investimento em Ações em geral, uma nova série de cálculos foi executada, diferenciando as transações efetuadas pelos fundos de investimento em ações destinados a investidores qualificados daquelas efetuadas pelos fundos de varejo. Os cálculos foram feitos mensalmente considerando cada ação detida pela carteira de cada fundo individualmente para depois serem agregados para todo o período sob análise.

Na tabela 3 e 4 podemos observar o teste do efeito disposição por transação respectivamente para fundos de investidores qualificados e para fundos de varejo. $\mathrm{O}$ teste E refere-se ao PGR e PPR calculados em suas bases ponderadas, enquanto o teste $\mathrm{F}$ considera uma média aritmética mensal dos percentuais, com o intuito de eliminar o efeito que meses atípicos podem causar nos resultados. Os mesmos testes $\mathrm{E}$ e $\mathrm{F}$ foram aplicados para os fundos de varejo, os quais resultaram nos testes $\mathrm{G}$ e $\mathrm{H}$.

Os resultados foram interessantes, pois de acordo com a tabela 3 verifica-se que no caso dos fundos de investidores qualificados, onde se esperava um comportamento mais racional, o efeito disposição foi constatado com relevante significância estatística em ambos os testes (E e F). Já nos fundos de varejo, a hipótese nula de que o percentual de ganhos realizados é menor ou igual ao percentual de perdas realizadas, não pôde ser rejeitada tanto no teste $\mathrm{G}$ como no $\mathrm{H}$, como pode ser observado na tabela 4 . 
Tabela 3

Teste estatístico do efeito disposição por transação nos fundos para investidores qualificados

\begin{tabular}{ccccccccc}
\hline Teste & GNR+GR & PNR+PR & GR & PR & PGR & PPR & PGR-PPR & $t$ \\
\hline E & 84.215 & 31.383 & 41.184 & 14.486 & $48,90 \%$ & $46,16 \%$ & $2,74 \%$ & 8,31 \\
F & 84.215 & 31.383 & 41.184 & 14.486 & $48,61 \%$ & $46,31 \%$ & $2,30 \%$ & 6,96 \\
\hline
\end{tabular}

Tabela 4

Teste estatístico do efeito disposição por transação nos fundos de varejo

\begin{tabular}{ccccccccc}
\hline Teste & GNR+GR & PNR+PR & GR & PR & PGR & PPR & PGR-PPR & $t$ \\
\hline E & 75.405 & 30.239 & 36.908 & 15.273 & $48,95 \%$ & $50,51 \%$ & $-1,56 \%$ & $(4,59)$ \\
F & 75.405 & 30.239 & 36.908 & 15.273 & $49,61 \%$ & $49,47 \%$ & $0,14 \%$ & 0,40 \\
\hline
\end{tabular}

Seguindo os passos anteriores com a justificativa de que considerar o volume transacionado para calcular as proporções de ganhos e perdas realizadas parece ser a melhor forma de se testar o efeito disposição, os testes com volume foram refeitos para a base segmentada.

Na tabela 5 são mostrados os resultados dos testes adicionais de volume efetuados com as carteiras dos fundos de investimento destinados a investidores qualificados e na tabela 6 podemos ver os mesmos testes com os fundos de varejo.

Tabela 5

Teste estatístico do efeito disposição por transação nos fundos de varejo

\begin{tabular}{ccccccc}
\hline Teste & GNR+GR & PNR+PR & GR & PR & GR(\%) & PR(\%) \\
\hline I & 123.850 .046 .849 & 12.492 .580 .780 & 8.154 .798 .544 & 1.026 .786 .171 & $6,58 \%$ & $8,22 \%$ \\
J & 123.850 .046 .849 & 12.492 .580 .780 & 8.154 .798 .544 & 1.026 .786 .171 & $6,28 \%$ & $7,81 \%$ \\
\hline
\end{tabular}

Conforme podemos observar no teste I da tabela 5, não se pode verificar a existência do efeito disposição por volume nos fundos para investidores qualificados, já que a Proporção de Ganhos Realizados $(6,58 \%)$ é menor que a Proporção das Perdas Realizadas $(8,22 \%)$. Os percentuais mostrados na tabela anterior revelam que, embora o resultado do teste com os fundos destinados a investidores qualificados seja o mesmo obtido no teste realizado com a base integral (teste $\mathrm{C}$ na tabela 2), a magnitude da diferença entre PPR e PGR é muito menor para tais fundos (1,64 pontos percentuais) em relação aos resultados quando a base toda é considerada (3,76 pontos percentuais). Mesmo quando PPR e PGR são calculados considerando-se suas médias aritméticas mensais, não é possível identificar o efeito disposição, embora a magnitude da diferença de tais percentuais seja um pouco menor (1,53 pontos percentuais), conforme mostra o teste $\mathrm{J}$ da tabela 5 .

Na tabela 6 são mostrados os mesmos testes do efeito disposição por volume, aplicados para os fundos de varejo. Conforme mostram os testes K e L, os resultados são, em suma, os mesmos obtidos anteriormente, ou seja, não há rejeição da hipótese nula descrita na equação (4) e, portanto não é possível constatar o efeito disposição. 
Tabela 6

Teste estatístico do efeito disposição por volume nos fundos de varejo

\begin{tabular}{ccccccc}
\hline Teste & GNR+GR & PNR+PR & GR & PR & GR(\%) & PR(\%) \\
\hline I & 116.254 .109 .235 & 7.436 .552 .172 & 5.386 .280 .684 & 792.701 .405 & $4,63 \%$ & $10,66 \%$ \\
J & 116.254 .109 .235 & 7.436 .552 .172 & 5.386 .280 .684 & 792.701 .405 & $6,04 \%$ & $10,80 \%$
\end{tabular}

De maneira similar à estruturação dos testes anteriores, enquanto o teste K considera os valores agregados de ganhos e perdas realizadas em todo o período para se calcular os percentuais PGR e PPR, o teste L considera os percentuais mensais de ganhos e perdas realizadas e cada mês possui o mesmo peso no cálculo de PGR e PPR, que representam a média aritmética dos respectivos percentuais mensais. $\mathrm{O}$ teste $\mathrm{K}$, quando comparado com os testes I (carteiras dos fundos destinados a investidores institucionais) e C (carteiras de todos os fundos de ações), revela que os fundos de varejo são os que apresentam a maior magnitude de diferença entre PPR e PGR (6,03 pontos percentuais), mostrando que esses são os fundos menos sujeitos ao efeito disposição.

As tabelas 1 a 6 mostraram os percentuais de ganhos e perdas realizadas pelos fundos de varejo e fundos destinados a investidores qualificados. A partir desses resultados, foram também calculados os percentuais de realização em faixas de ganhos ou perdas, com o intuito de verificar se os fundos realizam seus ganhos mais rapidamente que suas perdas.

As tabelas 7 e 8 a seguir mostram os percentuais de ganhos e perdas da quantidade de negócios que foram realizados entre as faixas de resultado pré-estabelecidas.

\section{Tabela 7}

Percentual de transações realizadas pelos fundos para investidores qualificados, por faixa de resultado bruto obtido

\begin{tabular}{cccc}
\hline & 0 a $5 \%$ & $5 \%$ a $10 \%$ & Acima de $10 \%$ \\
\hline GR & $12,77 \%$ & $12,94 \%$ & $74,29 \%$ \\
PR & $33,15 \%$ & $26,23 \%$ & $40,62 \%$ \\
\hline & 0 a $10 \%$ & $10 \%$ a $20 \%$ & Acima de $20 \%$ \\
\hline GR & $36,81 \%$ & $24,01 \%$ & $39,18 \%$ \\
PR & $74,99 \%$ & $20,34 \%$ & $4,67 \%$ \\
\hline
\end{tabular}

Nota: GR: Ganhos Realizados; PR: Perdas Realizadas. 
Tabela 8

Percentual de transações realizadas pelos fundos de varejo, por faixa de resultado bruto obtido

\begin{tabular}{cccc}
\hline & 0 a 5\% & $5 \%$ a $10 \%$ & Acima de $10 \%$ \\
\hline GR & $14,01 \%$ & $13,38 \%$ & $72,61 \%$ \\
PR & $31,69 \%$ & $25,47 \%$ & $42,84 \%$ \\
\hline & 0 a $10 \%$ & $10 \%$ a $20 \%$ & Acima de $20 \%$ \\
\hline GR & $27,39 \%$ & $20,75 \%$ & $51,86 \%$ \\
PR & $57,16 \%$ & $27,03 \%$ & $15,81 \%$ \\
\hline & 0 a $15 \%$ & $15 \%$ a $30 \%$ & Acima de 30\% \\
\hline GR & $38,88 \%$ & $24,48 \%$ & $36,64 \%$ \\
PR & $72,57 \%$ & $23,26 \%$ & $4,17 \%$ \\
\hline
\end{tabular}

A análise das tabelas anteriores mostra que há uma grande concentração de realização de ganhos nos negócios em que o resultado é superior a 10\%, tanto nos fundos de varejo quanto nos fundos destinados a investidores qualificados. Por outro lado, percebe-se que as perdas são realizadas em maior número quando o ativo cai até $15 \%$, mostrando velocidade na realização de perdas com base no número de transações realizadas.

As tabelas 9 e 10 a seguir revelam os mesmos cálculos mostrados nas tabelas 7 e 8, porém, aplicados sobre os percentuais de ganhos e perdas realizadas com base nos volumes transacionados pelos Fundos de Investimento em Ações.

Tabela 9

Percentual do volume de ganhos e perdas realizadas pelos fundos para investidores qualificados, por faixa de resultado bruto obtido

\begin{tabular}{cccc}
\hline & 0 a $5 \%$ & $5 \%$ a $10 \%$ & Acima de $10 \%$ \\
\hline GR & $1,32 \%$ & $3,10 \%$ & $95,58 \%$ \\
PR & $9,25 \%$ & $18,62 \%$ & $72,13 \%$ \\
\hline & 0 a $10 \%$ & $10 \%$ a $20 \%$ & Acima de $20 \%$ \\
\hline GR & $4,41 \%$ & $10,77 \%$ & $84,82 \%$ \\
PR & $27,87 \%$ & $28,43 \%$ & $43,70 \%$ \\
\hline & 0 a $15 \%$ & $15 \%$ a $30 \%$ & Acima de $30 \%$ \\
\hline GR & $8,95 \%$ & $17,40 \%$ & $73,65 \%$ \\
PR & $41,58 \%$ & $28,57 \%$ & $29,85 \%$ \\
\hline
\end{tabular}

O resultado apresentado na tabela 9 mostra que os fundos destinados a investidores qualificados realizam a maior parte $(73,65 \%)$ de seus ganhos quando estes apresentam altas superiores a 30\%, o que mostra uma propensão pela manutenção de ganhos.

A tabela 10, assim como a tabela 9, mostra que mais de um terço do volume de perdas realizadas pelos fundos, acontece com as ações que apresentam quedas até $15 \%$, indicando que as perdas são realizadas de forma mais rápida quando comparada à realização de ganhos. 


\begin{tabular}{cccc}
\hline & 0 a $5 \%$ & $5 \%$ a $10 \%$ & Acima de $10 \%$ \\
\hline GR & $1,65 \%$ & $3,50 \%$ & $94,85 \%$ \\
PR & $7,16 \%$ & $16,62 \%$ & $76,22 \%$ \\
\hline & 0 a $10 \%$ & $10 \%$ a $20 \%$ & Acima de $20 \%$ \\
\hline GR & $5,15 \%$ & $10,49 \%$ & $84,36 \%$ \\
PR & $23,78 \%$ & $29,83 \%$ & $46,40 \%$ \\
\hline & 0 a $15 \%$ & $15 \%$ a $30 \%$ & Acima de $30 \%$ \\
\hline GR & $9,87 \%$ & $19,37 \%$ & $70,76 \%$ \\
PR & $38,28 \%$ & $29,68 \%$ & $32,04 \%$ \\
\hline
\end{tabular}

\section{Conclusões}

Com base nos resultados apresentados anteriormente, não é possível identificar o efeito disposição nos fundos de investimento em ações, quando são considerados os volumes transacionados, o que mostra um comportamento distinto daquele verificado no mercado americano, conforme relatam os estudos discutidos no referencial teórico, principalmente os trabalhos de Odean (1998) e Barber e Odean (1999).

Quando é considerado apenas o número de transações realizadas pelos fundos de investimentos para o cômputo do percentual de ganhos e perdas realizadas, a hipótese nula de que o percentual de ganhos realizados é menor ou igual ao percentual de perdas realizadas é rejeitada, porém com baixa significância estatística quando comparada com estudos realizados no mercado americano.

Isso quer dizer que os fundos de investimento em ações transacionam mais os seus ganhos, porém em volume muito inferior que aquele verificado nas transações com ações perdedoras.

Quando a base de dados é dividida em duas categorias de fundos denominadas fundos de varejo e fundos destinados a investidores qualificados, ainda assim não é possível verificar o efeito disposição em qualquer das categorias, quando considerado o volume transacionado. Embora não haja rejeição da hipótese nula nas duas categorias, os fundos de varejo mostram-se muito menos sujeitos ao efeito disposição já que apresentam uma diferença entre PGR e PPR de 6,03 pontos percentuais, quando considerado o volume agregado no período analisado, enquanto os testes com fundos destinados a investidores qualificados revelam uma diferença de apenas 1,64 pontos percentuais.

Em outras palavras, pode-se dizer que os testes realizados com as carteiras dos fundos de investimento em ações mostram que esses investidores tenderam a liquidar mais rapidamente suas posições quando elas eram perdedoras do que quando eram vencedoras, ou seja, apresentaram aversão ao risco no campo das perdas e propensão ao risco do campo dos ganhos, justamente o oposto do que reza o efeito disposição.

Se há uma crença de que o mercado segue uma direção e não tende a reverter 
a uma média de curto, médio ou longo prazo, os fundos analisados revelam certa racionalidade, já que as movimentações dos ativos que compõem as carteiras dos fundos de varejo mostram que tais fundos mantêm as ações ganhadoras em magnitude muito maior que as perdas. Conforme visto nas conclusões anteriores, os testes estatísticos realizados neste trabalho mostram que os fundos de investimento em Ações realizam um maior número de transações com ganhos, porém em volume financeiro muito menor que as transações realizadas com ações perdedoras. A partir desses resultados pode-se supor que os fundos de investimento em ações gerem suas carteiras com base numa expectativa de que o mercado acionário brasileiro esteja sujeito ao efeito "momentum".

Este fato pode estar relacionado a uma tendência dos fundos de investimento em Ações em venderem seus ganhos para quitar despesas recorrentes de administração e gestão do fundo e, por outro lado, venderem suas perdas em momentos de mudanças nas tendências de mercado (aumento da taxa básica de juros, por exemplo) onde haja grande saída de recursos dos fundos para outros investimentos.

O maior número de transações com ativos ganhadores observado também pode estar relacionado a uma necessidade dos fundos em rebalancearem as suas carteiras. Muitos fundos têm como benchmark ${ }^{5}$ algum índice cuja composição é alterada com prazos determinados, como o Ibovespa ou IBrX-50 por exemplo. Assim, para que o fundo acompanhe essas referências, deve manter os ativos em suas carteiras nas mesmas proporções em que as mesmas integram tais indicadores. Desta forma, se um ativo qualquer sofre uma alta muito maior que o esperado, o seu percentual na carteira do fundo também se eleva, sendo necessária uma venda parcial deste ativo para rebalancear a carteira. De forma similar, se um ativo se deprecia muito, deve ser recomprado para rebalancear a carteira ou, caso não haja recursos suficientes, ativos com ganhos serão vendidos, contribuindo para um aumento na contagem de transações com ganhos.

De qualquer forma, se os fundos de investimentos não estão sujeitos ao efeito disposição e o mercado acionário brasileiro for de momento e não tender a uma reversão à média no curto prazo, então pode ser que uma carteira formada pela compra dos ativos com ganhos e venda dos ativos com perdas que são detidas pelos fundos de investimento em Ações apresente retornos anormais de curto prazo. Esta é uma das recomendações para trabalhos futuros.

O presente artigo considerou a divisão da base entre duas categorias de fundos de investimento em Ações: os de varejo e os destinados a investidores qualificados. Estudos futuros podem segmentar a mesma base utilizada pelos administradores dos fundos, que podem apresentar comportamentos distintos entre si. Assim, seria possível identificar aqueles fundos que estão mais ou menos sujeitos ao efeito disposição. Esse resultado analisado em conjunto com a performance dos administradores pode ser bastante útil na criação de carteiras hipotéticas que busquem retornos anormais.

${ }^{5} \mathrm{O}$ benchmark é a referência em relação à qual os resultados dos fundos de investimento são avaliados. 
A base de dados também poderia ser segmentada entre os fundos de gestão ativa e aqueles de gestão passiva, ou seja, os que apenas acompanham certo indicador. Esses resultados segmentados podem mostrar se a realização de perdas é fruto de estratégia do gestor ou são "forçadas" pelo regulamento do fundo quando o mesmo precisa acompanhar o indicador estabelecido.

Embora não haja base de dados disponível para replicar o presente artigo num período de queda do mercado acionário, um estudo comparativo poderia trazer informações relevantes acerca da aptidão dos gestores para admitir melhor as perdas quando o mercado é de alta.

Estudos futuros também poderiam contemplar ativos de menor liquidez no intuito de se avaliar se os fundos de investimento se comportam de forma distinta para tais ativos. Essa análise ganha mais importância a partir do momento em que o país atingiu o grau de investimento, o que pode provocar uma maior procura por ações menos líquidas, especialmente se houver uma procura abundante que promova saturação das blue chips. ${ }^{6}$

\section{Referências}

Accorsi, A., Neto, J. M., \& Decourt, R. F. (2007). Behavioral finance and the investment decision-making process in the Brazilian financial market. The Icfai Journal of Behavioral Finance, 4:59-74.

Ackert, L. \& Deaves, R. (2010). Behavioral Finance: Psychology, DecisionMaking, and Markets. South Western, Mason. OH, 432 p.

Allais, M. (1953). Le comportement de l'homme rationnel devant le risque: Critique des postulats et axiomes de L'école Américaine. Econometrica, 21:503546.

ANBID (2008). Fundos de investimentos. Disponível em: http: //www . anbid . com. br/. Acesso em: 05/01/2008.

Barber, B. M., Lee, Y.-T., Liu, Y.-J., \& Odean, T. (2007). Is the aggregate investor reluctant to realize losses? Evidence from Taiwan. European Financial Management, 13:423-447.

Barber, B. M. \& Odean, T. (1999). The courage of misguided convictions: The trading behavior of individual investors. Financial Analysts Journal, 55:41-55.

Barber, B. M. \& Odean, T. (2001). Boys will be boys: Gender, overconfidence, and common stock investment. Quarterly Journal of Economics, 116:261-292.

\footnotetext{
${ }^{6}$ Também chamadas de primeira linha, são ações de empresas tradicionais, negociadas com frequência nos pregões e que mantêm uma valorização no longo prazo. É um jargão do pôquer, que chama dessa forma as fichas mais valiosas do jogo.
} 
Barberis, N. \& Thaler, R. (2003). A survey of behavioral finance. In Constantinides, G. M., Harris, M., \& Stulz, R. M., editors, Handbook of the Economics of Finance, pages 1053-1128. Elsevier, Amsterdam.

Barberis, N. \& Xiong, W. (2009). What drives the disposition effect? Journal of Finance, 64:751-784.

BMFBOVESPA (2010). Metodologia completa do IBrX-50. Disponível em: http://bmf bovespa.com.br/indices. Acesso em: 25/03/2010.

Boebel, R. B. \& Taylor, L. (2000). The disposition effect: Do New Zealand investors keep their mistakes? Working Paper Department of Finance and Quantitative Analysis, University of Otago, New Zealand.

Brown, P., Chappel, N., Rosa, R. S., \& Walter, T. (2006). The reach of the disposition effect: Large sample evidence across investor classes. International Review of Finance, 6:43-78.

Choe, H. \& Eom, Y. (2009). The disposition effect and investment performance in the futures market. Journal of Futures Markets, 29:496-522.

Da Costa Jr., N. C. A., Da Silva, S., Cupertino, C. M., \& Goulart, M. A. O. (2008), Efeito disposição e experiência: Um teste de laboratório no Brasil. In Anais Do XXXII Encontro Da Associação Nacional de Pós-Graduação e Pesquisa Em Administração - ANPAD. Rio de Janeiro.

De la Torre, A., Gozzi, J. C., \& Schmukler, S. L. (2008). Capital market development: Whither Latin America? In Edwards, S. \& Garcia, M. G. P., editors, Financial Markets Volatility and Performance in Emerging Markets, pages 121154. The University of Chicago Press, Chicago.

Fama, E. (1970). Efficient capital markets: A review of theory and empirical work. Journal of Finance, 25:383-417.

Ferris, S. P., Haugen, R. A., \& Makhija, A. K. (1988). Predicting contemporary volume with historic volume at differential price levels: Evidence supporting the disposition effect. Journal of Finance, 43:677-697.

Filho, R. M. (2008). Mercado de capitais: Desenvolvimento sustentável. In Rocca, C. A., editor, A Revolução No Mercado de Capitais No Brasil: O Crescimento Recente É Sustentável?, pages 1-4. Elsevier, Rio de Janeiro.

Grinblatt, M. \& Keloharju, M. (2001). What makes investors trade? Journal of Finance, 56:589-616.

Kahneman, D. \& Riepe, M. V. (1998). Aspects of investor psychology - beliefs, preferences and biases investment advisors should know about. Journal of Portfolio Management, 24:52-65. 
Kahneman, D., Slovic, P., \& Tversky, A. (1982). Judgement under Uncertainty: Heuristics and Biases. Cambridge University Press, Cambridge, New York and Sidney.

Kahneman, D. \& Tversky, A. (1979). Prospect theory: An analysis of decision under risk. Econometrica, 47:263-291.

Karsten, J. G. (2005). O efeito disposição: Um estudo empírico no Brasil. Fundação Getulio Vargas: Escola de Economia de São Paulo. Dissertação de Mestrado.

Locke, P. R. \& Mann, S. C. (2000). Do professional traders exhibit loss realization aversion? Working Paper Finance Department, School of Business and Public Management, The Georgetown University, Washington DC.

Macedo Jr., J. S. (2003). Teoria do prospecto: Uma investigação utilizando simulação de investimentos. Programa de Pós-Graduação em Engenharia de Produção, Universidade de Santa Catarina.

Markowitz, H. (1952). Portfolio selection. Journal of Finance, 7:77-91.

Miller, M. H. \& Modigliani, F. (1961). Dividend policy, growth and the valuation of shares. Journal of Business, 34:411-433.

Mineto, C. A. L. (2005). Percepção ao risco e efeito disposição: Uma análise experimental da teoria dos prospectos. Programa de Pós-Graduação em Engenharia de Produção, Universidade de Santa Catarina.

Nofsinger, J. R. (2001). Investment Madness: How Psychology Affects Your Investing... and What to Do About It. Prentice Hall, Upper Saddle River, New Jersey.

Odean, T. (1998). Are investors reluctant to realize their losses? Journal of Finance, 53:1775-1798.

Odean, T. (1999). Do investors trade too much? American Economic Review, 89:1279-1298

Shapira, Z. \& Venezia, I. (2001). Patterns of behavior professionally managed and independent investors. Journal of Banking and Finance, 25:1573-1587.

Sharpe, W. F. (1964). Capital asset prices: A theory of market equilibrium under conditions of risk. Journal of Finance, 19:425-443.

Shefrin, H. \& Statman, M. (1985). The disposition to sell winners too early and ride losers too long: Theory and evidence. Journal of Finance, 40:777-790.

Tversky, A. \& Kahneman, D. (1974). Judgement under uncertainty: Heuristics and biases. Science, 185:1124-1131. 
Velloso, J. P. R. (2008). Revolução no mercado de capitais do Brasil - e como torná-la sustentável (inclusive considerando as turbulências internacionais). In Rocca, C. A., editor, A Revolução No Mercado de Capitais No Brasil: O Crescimento Recente É Sustentável?, pages VII-IX. Elsevier, Rio de Janeiro.

Wald, A. (2008). A evolução do mercado financeiro e de capitais (1998-2008). Revista de Direito Bancário e do Mercado de Capitais, 11:11-13. 


\section{Apêndice}

Lista dos Códigos na Bolsa das 28 Ações usadas para na Formação das Carteiras Teóricas

\begin{tabular}{c}
\hline Código \\
\hline AMBV4 \\
ARCZ6 \\
BBAS3 \\
BBDC4 \\
BRAP4 \\
BRKM5 \\
BRTO4 \\
BRTP4 \\
CMIG4 \\
CPLE6 \\
CSNA3 \\
ELET3 \\
ELET6 \\
GGBR4 \\
ITAU4 \\
ITSA4 \\
KLBN4 \\
PETR3 \\
PETR4 \\
SBSP3 \\
SDIA4 \\
USIM5 \\
TCSL4 \\
TNLP3 \\
TNLP4 \\
VALE3 \\
VALE5 \\
VCPA4 \\
\hline
\end{tabular}

